\title{
Differences in procrastination and motivation between undergraduate and graduate students
}

\begin{abstract}
$\mathrm{Li} \mathrm{Cao}{ }^{1}$
Abstract: Procrastination became increasingly prevalent among students in recent years. However, little research was found that directly compares academic procrastination across different academic grade levels. The present study used a self-regulated learning perspective to compare procrastination types and associated motivation between undergraduate and graduate students. Sixty-six undergraduate and sixty-eight graduate students responded to a packet of questionnaires concerning their experience in an educational psychology class. The results show that students' beliefs about the usefulness of procrastination were a better predictor of academic procrastination than self-efficacy beliefs and achievement goal orientations. Student age was related to procrastination types. Among the undergraduate procrastinators, the younger students were more likely to engage in active procrastination while the older students tended to engage in passive procrastination. Implications and future research directions are discussed.
\end{abstract}

Keywords: procrastination, motivation, self-regulated learning, college students

\section{Introduction.}

Despite considerable research describing negative consequences, procrastination has become increasingly prevalent among university students in recent years (Harriort \& Ferrari, 1996; Knaus, 2000; Steel, 2007). Procrastination refers to the lack or absence of self-regulated performance and the behavioral tendency to postpone what is necessary to reach a goal (Knaus, 2000). Procrastination has long been viewed as a self-handicapping behavior that leads to wasted time, increased stress, and poor academic performance (Özer, 2011; Solomon \& Rothblum, 1984; Tice \& Baumeister, 1997; Wang \& Englander, 2010). Research demonstrates that academic procrastination impacts both undergraduate and graduate students.

Over $70 \%$ of undergraduate students admitted to procrastinating on their academic tasks (Ellis \& Knaus, 1977; Schouwenburg, 1995), while more than 50\% of them procrastinated consistently and problematically (Day, Mensink, \& O'Sullivan, 2000; Ferrari, O'Callaghan, \& Newbegin, 2005). Most recently, Klassen, et al. (2010) reported that about 58\% of their undergraduate participants "report[ed] spending three hours or more per day in procrastination" (p. 372). Solomon and Rothblum (1984) found that undergraduate students procrastinated more often when writing term papers (46\%) than when reading weekly assignments (30\%) and studying for examinations (28\%); and that (self-reported) fear of failure and task aversiveness were the two main reasons why undergraduate students procrastinated. Research shows that undergraduate student procrastination is related to gender, laziness, and difficulty in making decisions (Özer, Demir, \& Ferrari, 2009; Schouwenbury, 2004), perfectionism and control

1 Department of Educational Innovation University of West Georgia, 1601 Maple Street Carrollton, GA 30118, phone (678)-8396118, fax (678)-839-6153, E-mail: 1cao@westga.edu 
(Burns, Dittmann, Nguyen, \& Mitchelson, 2000), and the ability to resolve role conflict between school and interpersonal relationships (Senécal, Julien, \& Guay, 2003). Studies consistently show positive correlations between procrastination and undesirable behaviors or affective outcomes, such as failure to complete assignments, lower grades, low self-esteem, and higher stress (Ferrari, 2001; Schraw, Wadkins, \& Olafson, 2007; Tice \& Baumeister, 1997).

Academic procrastination is also a severe problem for graduate students (Collins \& Veal, 2004; Jiao, DaRos-Voseles, Collins, \& Onwuegbuzie, 2011; Onwuegbuzie \& Jiao, 2000). Disturbingly, Onwuegbuzie (2004) found that graduate students tended to procrastinate more than undergraduate students. In graduate students, procrastination was associated with (selfreported) fear of failure, task aversiveness, reading ability, self-efficacy (Collins, Onwuegbuzie, \& Jiao, 2008), and various types of academic-related anxiety (Onwuegbuzie, 2004; Onwuegbuzie \& Collins, 2001; Onwuegbuzie \& Jiao, 2000). Procrastination has a negative impact on graduate students' academic achievement (Onwuegbuzie, 2000) and grade point averages (Prohaska, Morrill, Atiles, \& Perez, 2000).

Research also shows that undergraduate students perceive their procrastination tendencies are a barrier to academic success in college (Fritzsche, Rapp \& Hickson, 2003; Kachgal et al., 2001). Similarly, between 65 and $75 \%$ of graduate students wanted to decrease their procrastination (Onwuegbuzie, 2004). Despite students' motivation and extensive research efforts to curtail this debilitating habit, academic procrastination has become increasingly prevalent, which suggests that procrastination is not entirely understood, and more research is needed (Kachgal, Hansen, \& Nutter, 2001; Steel, 2007).

As seen, an extensive body of research has examined the prevalence, reasons, and consequences of academic procrastination in undergraduate and graduate students. Surprisingly, no study has directly compared procrastination in undergraduate and graduate students, except Onwuegbuzie (2004) and Özer (2011). Onwuegbuzie (2004) reported that graduate students demonstrated an even greater tendency to procrastinate on academic tasks (3.5 times in keeping up with weekly reading assignments and 2.28 times in studying for examinations) than undergraduate students (Onwuegbuzie, 2004). However, Onwuegbuzie's (2004) findings were based comparison of the graduate student data he collected recently with the undergraduate student data that Solomon and Rothblum (1984) observed two decades ago. Onwuegbuzie's (2004) approach to data collection and analysis raised a concern that the prevalence of procrastination among the current undergraduate students might be underestimated, since frequency of procrastination among the undergraduate students has increased in the past two decades (Harriort \& Ferrari, 1996; Knaus, 2000, Steel, 2007).

Contrary to Onwuegbuzie's (2004) findings, Özer (2011) found that undergraduate students claimed to procrastinate more than graduate students on studying for exams, writing term papers, and reading weekly assignments. The inconsistent findings of Onwuegbuzie (2004) and Özer (2011) suggest that more research is needed to study similarities and differences of procrastination in undergraduate and graduate students.

In addition to the methodological concern, the present study expanded the earlier focus on the nature, antecedents, etiology, and consequences of academic procrastination (Knaus, 2000; Sommer, 1990; Steel, 2007). More recently, this research has shifted its focus from treating academic procrastination as a self-defeating personality flaw (Ferrari, 1991; Lay, 1990; Milgram, Dangour, \& Raviv, 1992; Schouwenburg, 2004) to viewing academic procrastination as a complex phenomenon with cognitive, affective, and behavioral components (Rothblum, Solomon, \& Murakami, 1986; Schraw et al., 2007; Wolters, 2003). 
As a result of this conceptual shift, recent research stressed that motivational and cognitive factors must be considered together to understand academic procrastination (Howell \& Buro, 2009; Muszynski \& Akamatsu, 1991; Steel, 2007). For instance, Lee (2005) reported that intrinsic motivation had significant unique effects on procrastination. Brownlow and Reasinger (2000) found that low extrinsic motivation, together with perfectionism, external locus of control, and attribution style contributed to the tendency of delaying school tasks. Howell and Buro (2009; Howell \& Watson, 2007) investigated how academic procrastination was correlated with beliefs, ability, achievement goals, and learning strategies. Senécal et al., (1995) examined the extent that academic motivation predicted academic procrastination and they concluded that procrastination is a motivational problem that involves more than poor time management skills or trait laziness.

These results demonstrate that ascertaining student motivation associated with academic procrastination would contribute to a better understanding of academic procrastination and ultimately lead to effective interventions to reduce its negative impact on student learning. However, no research study has directly examined similarities and differences in motivation of academic procrastination between undergraduate and graduate students. The present study addressed this gap by comparing procrastination and motivation of undergraduate and graduate students simultaneously. To facilitate the comparison, two different types of procrastinators were distinguished: passive procrastinators and active procrastinators.

\section{Academic Procrastination}

Recent research noted that not all forms of procrastination lead to negative consequences and examined the adaptive values associated with procrastination (Bernstein, 1998; Ferrari, 1991; 1994). This research shows that procrastination is related to intrinsic motivation (Senécal et al., 1995). Students reported that course materials become less boring, more interesting, and more engaging when they procrastinate (Schraw et al., 2007). Other benefits of procrastination include freeing up time for planning and other activities, more concentrated effort, a greater sense of challenge, and peak experience immediately prior to exams (Knaus, 2000; Lay, Edwards, Parker, \& Endler, 1998; Schraw et al., 2007). Furthermore, procrastination does not necessarily affect the quality of performance. For instance, Solomon and Rothblum (1984) found that there was no relationship between students' procrastination scores and their course grades. Similarly, Ferrari (1992) reported that procrastination scores were positively related to academic behavior delays but unrelated to exam scores. Pychyl, Morin, and Salmon (2000) concluded "Our results do not support the findings of previous research in this regard. There was no significant difference in exam performance between those students scoring high versus low on procrastination, despite the differences in the amount of time studied and onset of studying" (p. 147). These results suggest that procrastinators may also include those who choose to delay a task for the adaptive values of procrastination.

In line with this alternative view, Chu and Choi (2005) distinguished passive procrastinators and active procrastinators. Passive procrastinators were those who did not intend to procrastinate, but they often ended up postponing tasks because of their inability to make decisions quickly and to thereby act on them quickly. Active procrastinators were significantly different from passive procrastinators described in the traditional sense (Knaus, 2000; Senécal et al., 1995; Steel, 2007). Active procrastinators procrastinated because they preferred pressure and often used procrastination as a deliberate self-motivating strategy in order to be adequately 
motivated (Ferrari, Johnson, \& McGown, 1995). Because of their intention to accomplish the task and their ability to meet deadlines and produce satisfactory outcomes, the active procrastinators were believed to possess characteristics similar to non-procrastinators in managing their learning (Chu \& Choi, 2005; Choi \& Moran, 2009). The concept of active procrastination was included in the present study in order to examine the possible differences in procrastination and motivation between undergraduate and graduate students. More specifically, inclusion of active procrastination allowed the present study to examine whether active procrastination is associated with adaptive motivation factors, and whether active procrastinators actually performed better than passive procrastinators and non- procrastinators.

\section{Self-Regulated Learning Perspective}

The present study used a self-regulated learning perspective (Pintrich, 2000; Zimmerman, 2008) to examine how procrastination is related to motivation in undergraduate and graduate students. Self-regulated learning is described as an "active, constructive process whereby learners set goals for their learning and then attempt to monitor, regulate, and control their cognition, motivation, and behavior, guided and constrained by their goals and the contextual features in the environment' (Pintrich, 2000, p. 453). The self-regulated learning perspective was selected because it focuses on motivational, cognitive, and metacognitive processes of student learning (Pintrich, 2000; Wolters, 2003; Zimmerman \& Schunk, 2001). Guided by this framework, the present study examined whether active and passive procrastinators possess distinctive characteristics in self-efficacy, metacognitive beliefs, and achievement goal, as well as test performance in undergraduate and graduate students.

Self-efficacy. Self-efficacy refers to students' judgment of their capability to accomplish tasks and succeed in activities (Bandura, 1986, 1997). Bandura (1986) was the first to introduce the association between procrastination and self-efficacy beliefs. He posited that students possess the capabilities to regulate their thoughts and actions by reflecting on the outcomes of their learning process. However, students who were skeptical of their ability to exercise control over their behavior tend to undermine their own efforts to deal effectively with situations that challenge their capabilities (Bandura, 1986). Existing research supports Bandura's (1986) position that self-efficacy plays an important role in task initiation and persistence (Pintrich, 2000; Schraw et al., 2007; Schunk \& Pajares, 2005).

An inverse relationship was found between self-efficacy belief and academic procrastination among college students (Ferrari, Parker, \& Ware, 1992; Tuchman, 1991; Wolters, 2003). For instance, Tan et al., (2008) reported that self-efficacy for self-regulated learning was negatively correlated with procrastination. High self-efficacy for self-regulated learning also predicted students' expectations of doing well; low self-efficacy for self-regulated learning predicted students' expectations of not doing well academically. Similarly, Seo (2008) found that self-efficacy fully mediated the relationship between self-oriented perfectionism and academic procrastination, and that students with high self-oriented perfectionism procrastinated less than others. Furthermore, Chu and Choi (2005) found that self-efficacy was correlated negatively with passive procrastination, but positively with active procrastination, and that passive procrastinators had significantly lower self-efficacy than the active procrastinators. Exploring differences in the relationship between procrastination types and self-efficacy among undergraduate and graduate students would clarify how student judgment of academic capabilities influenced the tendency to procrastinate at different levels. 
Metacognitive beliefs. Recent research also shows that metacognitive beliefs play a role in procrastination (Fernie \& Spada, 2008). Metacognitive beliefs refer to the information individuals hold about their own cognition and internal states, as well as the coping strategies they activate in problematic situations (Wells, 2000; Wells \& Matthews, 1994, 1996). From a metacognitive standpoint, procrastinators are thought to delay or postpone action primarily because they doubt their own ability to complete a task, and they fear possible negative consequences of failing to adequately complete a task (Shoham-Saloman, Avner \& Neeman, 1989). Current theory has identified positive and negative metacognitive beliefs about procrastination (Fernie \& Spada, 2008; Spada, Hiou, \& Nikcevic, 2006). Positive metacognitive beliefs concern primarily the usefulness of procrastination in improving cognitive performance. They may include beliefs such as "Procrastination helps creative thinking" or "When I procrastinate, I am unconsciously mulling over difficult decisions." Such beliefs may predispose students to delay task initiation as a form of coping. Negative metacognitive beliefs concern primarily the uncontrollability of procrastination. They may include beliefs such as "Procrastination makes me feel down" or "When I procrastinate, I waste a lot of time thinking about what I am avoiding" (Fernie, Spada, Nikcevic, Georgiou \& Moneta, 2009). Such beliefs may perpetuate procrastination through predisposing students to intrusive thoughts and feelings which simultaneously consumes their cognitive resources necessary for concentration and controlling over thinking and coping (Fernie et al., 2009).

Specific positive and negative metacognitive beliefs about procrastination were found in chronic procrastinators in the general population (Spada, Hiou, \& Nikcevic, 2006). For instance, Spada, Hiou, and Nikcevic (2006) found that metacognitive beliefs about cognitive confidence ("My memory can mislead me at times") predicted behavioral procrastination, and that positive metacognitive beliefs about worry ("Worry can help me solve problems") predicted decisional procrastination. They postulated that individuals who hold negative beliefs about their cognitive efficiency may doubt their task performance capabilities. The latter are likely to adversely impact motivation as well as task initiation and persistence, leading to behavioral procrastination. Similarly, Fernie et al., (2009) found that positive metacognitive beliefs about procrastination were positively correlated with decisional procrastination. Negative metacognitive beliefs were positively correlated with both decisional and behavioral procrastination in undergraduate students. However, the influence of metacognitive beliefs about procrastination on students' behaviors and motivation has not been studied in graduate students, and no study has directly compared undergraduate and graduate students' metacognitive beliefs about procrastination.

Achievement goal orientation. The final motivational variable the present study examined was achievement goal orientations. Achievement goal orientations represent the different purposes or reasons for students to engage in achievement situations (Ames, 1984; Pintrich, 2000). These purposes direct student cognition and behavior across a range of academic tasks or learning situations, and determine how they approach and engage in learning activities (Ames, 1984). According to Elliot and McGregor's (2001) $(2 \times 2)$ achievement goal framework, a mastery-approach goal applies to the students who focus on improving ability, or thoroughly understanding new information. A mastery-avoidance goal applies to the students who strive to avoid failing to learn what there is to learn (Elliot \& Harackiewicz, 1996; Pintrich, 2000). A performance-approach goal applies to the students who focus on doing better than their peers, or proving their self-worth to other people (Ames \& Archer, 1988; Dweck, 1991; Moller \& Elliot, 2006). A performance-avoidance goal applies to the students who strive to avoid demonstrating a lack of competence with a particular topic (McGregor, \& Elliot, 2002; Midgley, Kaplan \&

Journal of the Scholarship of Teaching and Learning, Vol. 12, No.2, June 2012. 
Middleton, 2001). Students with performance-avoidance goal orientations are also concerned about how they compare with others. However, these students focus on avoiding the demonstration of their lack of ability, or preventing the perception that they are not competent with a particular topic or skill (McGregor, \& Elliot, 2002; Midgley et al., 2001).

In addition, work-avoidance goal orientation was included in the present study (Elliot, 1999; Maehr, 1983; Nicholls, Patashnick, \& Nolen, 1985). Work-avoidance goal orientation applies to students who strive to minimize their effort for academic tasks, prefer the tasks that can be completed quickly and easily, or prefer not to work too hard. Students with workavoidance goals tend to exhibit maladaptive motivation, cognitive and metacognitive strategies, and poor academic outcomes (Howell \& Watson, 2007; Meece \& Holt, 1993; Middleton \& Midgley, 1997; Wolters, 2003). Work-avoidance goal was included in the present study because it provided an index to detect students' motivational beliefs and behavior patterns of trying to get away with putting as little effort as possible into academic tasks (Wolters, 2003).

Current research of achievement goal orientations supports the view that procrastination is one specific self-handicapping behavior (Ferrari, 1992, 1994; Ferrari \& Tice, 2000; Ommundsen, 2001; Rhodewalt, 1994; Wolters, 2004). For instance, the mastery-approach goal was found to be related positively to higher levels of self-efficacy and help-seeking strategies (Pintrich, 2000; Schraw et al., 2007), but negatively to self-handicapping (Midgley, Arunkamar, \& Urdan, 1996; Pintrich, 2000) and procrastination in undergraduate students (Howell \& Watson, 2007; Wolters, 2003, 2004). Similarly, Midgley and Urdan (1995) found that self-handicapping was predicted negatively by a mastery goal orientation, but positively by performance-avoidance orientation. Other research shows that students may procrastinate more and have higher test anxiety under conditions that foster a mastery-avoidance orientation (Elliot \& McGregor, 2001; Howell \& Buro, 2009; Howell \& Watson, 2007), a performance-avoidance orientation (McGregor \& Elliot, 2002), or work-avoidance orientation (Blunt \& Pychyl, 1998; Clark \& Hill, 1994; Ferrari, 1991; Ferrari \& Tice, 2000; Wolters, 2003).

Contrary to the popular view of procrastination as a dysfunctional self-handicapping behavior, Chu and Choi (2005) argued that active procrastination is a self-regulatory behavior that some procrastinators intentionally engage in for adaptive values and positive outcomes. They described active procrastinators as possessing desirable characteristics similar to nonprocrastinators who maintain positive motivation toward the tasks and intend to learn and perform well in class. Nevertheless, Chu and Choi (2005) did not include achievement goal orientations in their study, and no research has examined the difference of achievement goal orientations between undergraduate and graduate students. To address this gap, the present study adopted a more comprehensive framework (i.e., Elliot \& McGregor's ( 2 x 2) model, plus workavoidance goal orientations, Maehr, 1983) to examine how achievement goal orientations relate to different types of procrastination (Chu \& Choi, 2005) in undergraduate and graduate students.

\section{The Present Study}

Recently, research on procrastination started to examine academic procrastination from the selfregulated learning perspective (Schraw et al., 2007; Senécal et al., 1995; Wolters, 2003, 2004). This research distinguished different procrastination types and examined motivation factors associated with passive and active procrastination (e.g., Chu \& Choi, 2005; Schraw et al., 2007). However, the existing research was limited mostly to a single educational level. The present study contributed to the literature by using a cross-sectional design to compare undergraduate 
and graduate students' procrastination types and the associated motivation variables in one subject-matter area. Controlling the subject-matter area allowed the present study to exclude the influence of different subject-matter disciplines on students' motivation and behaviors related to procrastination, and therefore would enhance validity of the study. Based on the self-regulated learning perspective, self-efficacy, metacognitive beliefs, and achievement goals were examined in the present study, because these motivational variables were expected to be predictors of procrastination. More importantly, because they are malleable student characteristics, future interventions can be designed to work on these variables (Banudra, 1997; Pintrich, 2000; Rakes \& Dunn, 2010; Wolters, 2003). For instance, if self-efficacy, metacognitive beliefs, and achievement goal are found to be predictive of procrastination, courses can be designed to take pre-emptive action against academic procrastination by promoting student academic confidence, increasing guidance for self-regulation, and facilitating learning goal orientation.

Understanding how different types of academic procrastination relate to these motivational factors in undergraduate and graduate students would allow faculty and staff to make concerted efforts to more effectively tackle this prevalent problem. Specifically, the present study addressed three research questions: (1) How procrastination types were associated with motivation for undergraduate and graduate students? (2) Which motivational factors predicted different types of procrastination for undergraduate and graduate students? (3) What were the differences in motivation among the different types of procrastinators between undergraduate and graduate students?

\section{Method.}

\section{A. Participants.}

Participants of the study included sixty-six undergraduate students and sixty-eight graduate students enrolled in two educational psychology classes in the College of Education at a fouryear university in the southeastern U.S. The same instructor taught both classes for undergraduate and graduate students, thereby minimizing the threat to internal validity due to instructor differences. Standard Institutional Review Board procedures were followed to ensure the privacy and anonymity of the participants. Of the 66 undergraduate students, $82 \%$ (54) were female and $18 \%$ (12) male. Forty-three (80\%) participants identified themselves as Caucasian/White, ten (15\%) as Black, and three (5\%) as other. They majored in early childhood $(55 \%)$, middle grades (24\%), secondary (4\%), special education $(7 \%)$, and other majors $(10 \%)$. Their age ranged from 20 to $59(M=27.21, S D=9.28)$, suggesting that the sample included a considerable number of nontraditional students.

Of the 68 graduate students, 84\% (57) were female and 16\% (11) male. Forty-three (64\%) identified themselves as White, eighteen (27\%) as Black, and five (9\%) as Hispanic and other. They majored in counseling (65\%) and other education majors (35\%; e.g., early childhood, art education, social studies, etc.). They ranged in age from 22 to $56(M=32.12, S D=9.04)$. Inclusion of older non-traditional students was expected in the graduate sample.

\section{B. Measurement and Procedure.}

Participants were invited to respond to a survey packet during the last class. The packet included the following measurement instruments. An Educational Psychology Self-Efficacy inventory 
consisting of eight items answered on a 5-point Likert scale. Participants were asked to indicate their level of agreement on each statement ranging from 1 (nothing like me) to 5 (a great deal like me). This self-developed questionnaire followed Bandura's $(1986,1997)$ guideline of selfefficacy scales and has been shown to be internally reliable in previous studies (e.g., Nietfeld, Cao, \& Osborne, 2006). Sample items included "I am sure that I can learn educational psychology" (Cronbach $\alpha=.79$ for the total; .92 for the graduate, and .68 for the undergraduate, hence after).

Metacognitive beliefs about Procrastination Questionnaire (Fernie et al., 2009) consisted of two-factors of eight items each measuring metacognitive beliefs about procrastination. The first factor (Cronbach $\alpha=.81 ; .74 / .86$ ) represented positive metacognitive beliefs about procrastination (e.g., Procrastination allows creativity to occur more naturally), while the second factor (Cronbach $\alpha=.80 ; .78 / .82$ ) represented negative beliefs about procrastination (e.g., Procrastination increases my worry). Participants were asked to express their level of agreement with the statement on a Likert scale ranging from 1 (not at all true) to 7 (very true).

Achievement Goal Orientations Questionnaire consisted of 16 items on a 7-point Likert scale (Cronbach alpha=.79;.79/.77). For each item, the participants read a short statement and then chose a number from 1 to 7 to indicate how strongly they agree (7) or disagree (1) with the statement. The questionnaire included 12 items (Elliot \& McGregor, 2001) that measured the mastery- and performance-approach vs. mastery- and performance-avoidance goal orientations, plus four items measuring the work-avoidance goal orientation (Wolters, 2003). A sample item of mastery-approach goal orientation read, "I want to learn as much as possible from this class." A sample mastery-avoidance goal orientation item included, "I worry that I may not learn all that I possibly could in this class." A sample performance-approach goal orientation item is, "My goal in this class is to get a better grade than most of the other students." A sample performanceavoidance goal orientation item included, "I just want to avoid doing poorly in this class." A sample work-avoidance goal orientation item read, "I like the class work best that I can finish quickly."

Academic Procrastination. Tuckman's (1991) 16-item Procrastination Scale (Cronbach $\alpha=.87 ; .90 / .83$ ) was used to measure "the tendency to waste time, delay, and intentionally put off something that should be done" (p. 479). Participants were asked to indicate agreement on a Likert scale ranging from 1 (not at all true to me) to 7 (very true to me) on a statement (e.g., "I needlessly delay finishing jobs, even when they're important.") of passive procrastination.

Active Procrastination. Choi and Moran's (2009) 16-item scale was used to identify active procrastinators (Cronbach $\alpha=.83 ; .73 / .86$ ). This 7-point Likert scale measures four defining characteristics of active procrastinators: (a) preference for pressure (e.g., "I tend to work better under pressure"), (b) intentional procrastination (e.g., "I intentionally put off work to maximize my motivation"), (c) ability to meet deadlines (e.g., "Since I often start working on things at the last moment, I have trouble finishing assigned tasks most of the time" [reverse coded]), and (d) outcome satisfaction (e.g., "I feel that putting work off until the last minute does not do me any good" [reverse coded]). A composite score of these four subscales was used to assess the overall tendency toward active procrastination.

\section{Results.}

Pearson correlation procedures were used to address the first research question: How procrastination types were associated with motivation for undergraduate and graduate students? 
Cao, L.

No significant correlation was found between academic procrastination and active procrastination either for undergraduate or graduate students, suggesting that the Academic Procrastination Scale and the Active Procrastination Scale measured different constructs.

As Table 1 shows, for undergraduate students, academic procrastination is positively correlated with positive metacognitive beliefs about procrastination $(r=.56, p<0.001)$, performance-avoidance goal orientation $(r=.29, p<0.019)$, and work-avoidance goal orientation $(r=.35, p<0.004)$; but negatively correlated with test performance $(r=-.26, p<0.038)$ and age $(r=-$ $.25, p<0.044)$. Active procrastination is positively correlated with positive metacognitive beliefs about procrastination $(r=.29, p<0.019)$; but negatively correlated with negative metacognitive beliefs about procrastination $(r=-.51, p<0.001)$ and mastery-approach goal orientation $(r=-.34$, $p<0.005)$.

Undergraduate students' educational psychology self-efficacy beliefs are positively correlated with test performance $(r=.46, p<0.001)$ and mastery-approach goal orientation $(r=.31$, $p<0.012)$; but negatively correlated with mastery-avoidance goal orientation $(r=-.42, p<0.001)$, performance-avoidance goal $(r=-.27, p<0.027)$, and work-avoidance goal $(r=-.25, p<0.044)$. Their positive metacognitive beliefs about procrastination are positively correlated with performance-avoidance $(r=.33, p<0.006)$ and work-avoidance goal orientation $(r=.41, p<0.001)$; but negatively correlated with test performance $(r=-.36, p<0.003)$, age $(r=-.37, p<0.003)$, and mastery-approach goal orientation $(r=-.39, p<0.001)$.

For graduate students, academic procrastination is positively correlated with positive metacognitive beliefs about procrastination $(r=.72, p<0.001)$, performance-avoidance goal orientation $(r=.39, p<0.001)$, and work-avoidance goal orientation $(r=.52, p<0.001)$; but negatively correlated with mastery-approach goal orientation $(r=-.32, p<0.008)$. Active procrastination is positively correlated with educational psychology self-efficacy ( $r=37$, $p<0.002)$. Their positive metacognitive beliefs about procrastination are positively correlated with mastery-avoidance goal orientation $(r=.27, p<0.028)$, performance-avoidance $(r=.42$, $p<0.001)$, and work-avoidance goal orientation $(r=.49, p<0.001)$; but negatively correlated with age $(r=-.35, p<0.004)$ and mastery-approach goal orientation $(r=-.25, p<0.042)$. Their negative metacognitive beliefs about procrastination are positively correlated with mastery-approach goal orientation $(r=.27, p<0.024)$.

A three-step hierarchical regression analysis was used to address the second question: Which motivational factors predicted different types of procrastination for undergraduate and graduate students? The hierarchical approach was selected over a forced entry or stepwise method, because this approach allowed selection of predictors for the theoretical reasons to examine the added influence of different motivational variables on procrastination (Field, 2009). Before the regression analysis was conducted, normality of the dataset was examined using methods described by Tabachnick and Fidell (2001). Specifically, the skewness and Kurtosis scores of the dependent variables of the regression models [i.e., the total scores of the Academic Procrastination Scale (Tuckman, 1991) and the Active Procrastination Scale (Choi \& Moran, 2009)] were examined for both undergraduate and graduate students. None of the skewness and the Kurtosis scores exceed 2.5 times of their corresponding standard errors (Morgan, Leech, Gloechner, \& Barrett, 2011), suggesting the dataset normality was not violated.

As Table 2 shows, positive metacognitive beliefs about procrastination were the sole predictor of academic procrastination for both undergraduate students in step one $(\beta=.56$, $\left.t_{(63)}=5.19, p<.001\right)$, step two $\left(\beta=.54, t_{(62)}=4.92, p<.001\right)$, and step three $\left(\beta=.50, t_{(57)}=3.75\right.$, $p<.001)$; and graduate students in step one $\left(\beta=.73, t_{(65)}=8.16, p<.001\right)$, step two $(\beta=.72$, 
$\left.t_{(64)}=8.03, p<.001\right)$, and step three $\left(\beta=.60, t_{(59)}=5.53, p<.001\right)$. The model explained $32 \%$ of the variance in academic procrastination score for undergraduate students and $51 \%$ for graduate students. In addition, Table 2 shows that for undergraduate students active procrastination was predicted by negative metacognitive beliefs about procrastination in step one $\left(\beta=-.47, t_{(63)}=-4.25\right.$, $p<.005)$, step two $\left(\beta=-.47, t_{(62)}=-4.26, p<.001\right)$, and step three $\left(\beta=-.45, t_{(57)}=-3.89, p<.001\right)$, plus mastery-approach goal orientations in step three $\left(\beta=-.32, t_{(57)}=-.2 .31, p<.025\right)$. For graduate students, active procrastination was predicted by positive metacognitive beliefs about procrastination $\left(\beta=.26, t_{(64)}=2.30, p<.025\right)$ and educational psychology self-efficacy $(\beta=.39$, $\left.t_{(64)}=3.48, p<.001\right)$ in step two; but only by educational psychology self-efficacy $(\beta=.36$, $\left.t_{(59)}=3.16, p<.002\right)$ in step three. The model explained $29 \%$ of the variance in active procrastination score for undergraduate students and $6 \%$ for graduate students.

In order to address the third research question about the differences in motivation among different types of procrastinators between undergraduate and graduate students, a two-step process (Chu \& Choi, 2005) was used to categorize the participants into three subgroups for undergraduate and graduate students. In the first step, participants' responses on Tuckman's (1991) Academic Procrastination Scale were used to distinguish procrastinators from nonprocrastinators among undergraduate students. The undergraduate participants who scored less than the median score (3.00) on the Tuckman Scale were grouped as non-procrastinators and those who scored equal or greater than 3.00 were grouped as procrastinators. Among the 66 undergraduate participants, 30 were categorized as non-procrastinators and 36 were categorized as procrastinators. In the second step, participants' responses on Choi and Moran's (2009) Active Procrastination Scale were used to distinguish passive procrastinators from active procrastinators. Among the 36 undergraduate procrastinators, those who scored less than the median score (3.75) on the Active Procrastination Scale were grouped as passive procrastinators $(n=16)$ and those who scored equal or greater than 3.75 were grouped as active procrastinators $(n=20)$. The same procedure was used to distinguish the procrastinator groups for the graduate students. Among the 68 graduate students, 33 were identified as non-procrastinators, 15 as passive procrastinators, and 20 as active procrastinators.

Analyses of covariate (ANCOVA) procedures were used to examine differences of the major variables among non-procrastinators, passive procrastinators, and active procrastinators separately for undergraduate and graduate students. Because the undergraduate group included nontraditional students $(M=27.21, S D=9.28)$ and a significant age difference was found among the three procrastination groups $\left(F_{(2,62)}=9.08, p=.004 ; \eta^{2}=.13\right)$, student age was used as a covariate to control the age effect on procrastination and motivation for the undergraduate group. For the undergraduate students, the ANCOVA results revealed a significant omnibus effect among the three procrastination groups on metacognitive beliefs, educational psychology selfefficacy, achievement goals, and test performance (Wilk's $\lambda=.54, F_{(2,62)}=2.15, p=.008, \eta^{2}=.26$ ). As Table 3 shows, a significant difference was found among the three procrastination groups in positive metacognitive beliefs about procrastination $\left(F_{(2,62)}=9.18, p=.001 ; \eta^{2}=.23\right)$; negative metacognitive beliefs about procrastination $\left(F_{(2,62)}=5,64, p=.006 ; \eta^{2}=.15\right)$; mastery-avoidance goal orientation $\left(F_{(2,62)}=3.50, p=.036 ; \eta^{2}=.10\right)$; and work-avoidance goal orientation $\left(F_{(2,62)}=4.19\right.$, $\left.p=.020 ; \eta^{2}=.12\right)$.

The Bonferroni procedures were used to further examine differences among the three groups. The pair-wise comparisons show that both active procrastinators (Group 3, $M=4.02, p$ $=.001$ ) and passive procrastinators (Group 3, $M=3.43, p=.040$ ) reported a significantly higher level of positive metacognitive beliefs about procrastination than the non-procrastinators (Group 
Table 1. Correlations among the major variables among undergraduate and graduate Students.

\begin{tabular}{|c|c|c|c|c|c|c|c|c|c|c|c|c|c|}
\hline & & 1 & 2 & 3 & 4 & 5 & 6 & 7 & 8 & 9 & 10 & 11 & 12 \\
\hline 1 & Test Performance & -- & $.33^{* *}$ & $-.26^{*}$ & .06 & $.46^{* *}$ & $-.36^{* *}$ & .10 & .17 & -.14 & .04 & $-.34^{* *}$ & -.17 \\
\hline 2 & Age & .24 & -- & $-.25^{*}$ & -.13 & .06 & $-.37^{* *}$ & -.03 & .24 & -.15 & -.22 & $-.37^{* *}$ & -.09 \\
\hline 3 & $\begin{array}{l}\text { Academic } \\
\text { Procrastination }\end{array}$ & -.16 & -.17 & -- & .19 & -.19 & $.56^{* *}$ & -.16 & -.16 & .08 & .08 & $.29^{*}$ & $.35^{* *}$ \\
\hline 4 & Active Procrastination & -.13 & -.02 & .14 & -- & .02 & $.29^{*}$ & $-.51^{* *}$ & $-.34^{* *}$ & -.20 & .08 & -.04 & .11 \\
\hline 5 & $\begin{array}{l}\text { Ed. Psychology Self- } \\
\text { Efficacy }\end{array}$ & .02 & .11 & -.16 & $.37^{* *}$ & -- & -.22 & .08 & $.31^{*}$ & $-.42^{* *}$ & .20 & $-.27^{*}$ & $-.25^{*}$ \\
\hline 6 & $\begin{array}{l}\text { Positive Beliefs About } \\
\text { Procrastination }\end{array}$ & -.18 & $-.35^{* *}$ & $.72^{* *}$ & .24 & -.08 & -- & -.24 & $-.39^{* *}$ & .09 & .12 & $.33^{* *}$ & $.41^{* *}$ \\
\hline 7 & $\begin{array}{l}\text { Negative Beliefs About } \\
\text { Procrastination }\end{array}$ & .15 & .24 & -.13 & -.10 & -.07 & -.23 & -- & .15 & .21 & -.07 & .14 & .00 \\
\hline 8 & Mastery Approach & .12 & $.34^{* *}$ & $-.32^{* *}$ & .11 & .14 & $-.25^{*}$ & $.27^{*}$ & -- & .19 & $.27^{*}$ & -.04 & -.22 \\
\hline 9 & Mastery Avoidance & $-.33^{* *}$ & -.08 & .17 & .15 & -.03 & $.27^{*}$ & -.02 & .19 & -- & -.00 & $.39^{* *}$ & .17 \\
\hline 10 & Performance Approach & .14 & -.24 & .24 & .22 & -.00 & .20 & -.13 & -.16 & .03 & -- & .19 & $.28^{*}$ \\
\hline 11 & Performance Avoidance & -.16 & $-.29^{*}$ & $.39^{* *}$ & .08 & -.13 & $.42^{* *}$ & -.17 & -.20 & .17 & .23 & -- & $.33^{* *}$ \\
\hline 12 & Work Avoidance & -.09 & $-.29^{*}$ & $.52^{* *}$ & .21 & -.06 & $.49^{* *}$ & -.17 & $-.52^{* *}$ & .00 & $.49^{* *}$ & $.42^{* *}$ & -- \\
\hline
\end{tabular}

Note: $* *=$ significant at 0.01 level; $*=$ significant at the 0.05 level (2-tailed). Correlational coefficients above the diagonal line represent undergraduate students $(\mathrm{n}=66)$ and those below the diagonal line represent graduate students $(\mathrm{n}=68)$. 
Table 2. Summary of hierarchical regression analyses predicting academic and active procrastination.

\begin{tabular}{|c|c|c|c|c|c|c|c|c|c|c|c|c|c|}
\hline \multirow{3}{*}{$\frac{\text { Model }}{\text { Step } 1}$} & & \multicolumn{6}{|c|}{ Academic Procrastination } & \multicolumn{6}{|c|}{ Active Procrastination } \\
\hline & & \multicolumn{2}{|c|}{$B$} & \multicolumn{2}{|c|}{ Std. Error } & \multicolumn{2}{|c|}{$\beta$} & \multicolumn{2}{|c|}{$B$} & \multicolumn{2}{|c|}{ Std. Error } & \multicolumn{2}{|c|}{$\beta$} \\
\hline & & Undr & Grad & Und & Grad & Undrg & Grad & Undrg & Grad & Undrg & Grad & Undrg & Grad \\
\hline & Positive Metacog. Beliefs about Procrast. & .62 & .60 & .12 & .07 & $.56^{* *}$ & $.73 * *$ & .14 & .21 & .08 & .12 & .18 & .22 \\
\hline & Negative Metacog. Beliefs about Procrast. & -.02 & .03 & .11 & .07 & -.02 & .04 & -.33 & -.05 & .08 & .12 & $-.47 * *$ & -.05 \\
\hline \multicolumn{14}{|l|}{ Step 2} \\
\hline & Positive Metacog. Beliefs about Procrasti. & .60 & .59 & .12 & .07 & $.54 * *$ & $.72 * *$ & .15 & .25 & .09 & .11 & .20 & $.26^{*}$ \\
\hline & Negative Metacog. Beliefs about Procrast. & -.02 & .03 & .11 & .07 & -.02 & .03 & -.33 & -.01 & .08 & .11 & $-.47 * *$ & -.01 \\
\hline & Educational Psychology Self-Efficacy & -.10 & -.19 & .16 & .16 & -.07 & -.10 & .11 & .82 & .11 & .24 & .10 & $.39 * *$ \\
\hline \multicolumn{14}{|l|}{ Step 3} \\
\hline & Positive Metacog. Beliefs about Procrasti. & .56 & .49 & .15 & .09 & $.50 * *$ & $.60 * *$ & .06 & .17 & .10 & .13 & .07 & .18 \\
\hline & Negative Metacog. Beliefs about Procrasti. & -.06 & .06 & .12 & .08 & -.06 & .07 & -.32 & -.05 & .08 & .11 & $-.45 * *$ & -.05 \\
\hline & Educational Psychology Self-Efficacy & -.08 & -.15 & .20 & .16 & -.06 & -.08 & .17 & .76 & .14 & .24 & .17 & $.36^{* *}$ \\
\hline & Mastery-Approach & .12 & -.08 & .12 & .09 & .13 & -.09 & -.19 & .23 & .08 & .14 & $-.32 *$ & .23 \\
\hline & Mastery-Avoidance & -.04 & .01 & .10 & .06 & -.06 & .02 & .01 & .05 & .07 & .08 & .01 & .07 \\
\hline & Performance-Approach & -.05 & .01 & .09 & .05 & -.07 & .02 & .04 & .08 & .06 & .08 & .09 & .12 \\
\hline & Performance-Avoidance & .08 & .03 & .10 & .05 & .11 & .05 & .0 & -.02 & .07 & .08 & .01 & -.04 \\
\hline & Work-Avoidance & .14 & .12 & .12 & .10 & .16 & .16 & .01 & .19 & .08 & .15 & .02 & .21 \\
\hline
\end{tabular}

Note: $* * p<.001 ; * p<.05$. Left column for undergraduate students $(\mathrm{n}=66)$ : for Academic Procrastination, $\Delta R^{2}=.32(p<.001)$ for Step $1 ; \Delta R^{2}=.00$ $(p<.001)$ for Step 2; $\Delta R^{2}=.03(p<.001)$ for Step 3. For Active Procrastination, $\Delta R^{2}=.29(p<.001)$ for Step $1 ; \Delta R^{2}=.01(p<.001)$ for Step 2. $\Delta R^{2}=.07$ $(p<.001)$ for Step 3. Right column for graduate students $(\mathrm{n}=68)$ : for Academic Procrastination, $\Delta R^{2}=.51(p<.001)$ for Step $1 ; \Delta R^{2}=.01(p<.001)$ for Step $2 ; \Delta R^{2}=.05(p<.001)$ for Step 3. For Active Procrastination, $\Delta R^{2}=.06(p=.15)$ for Step $1 ; \Delta R^{2}=.15(p<.002)$ for Step $2 ; \Delta R^{2}=.08(p<.008)$ for Step 3. 
Table 3. Mean, SD, and ANCOVA results of test performance, metacognitive beliefs about procrastination, self-efficacy, and achievement goal orientations of non-procrastinators, passive procrastinators, and active procrastinator with age as covariate.

\begin{tabular}{|c|c|c|c|c|c|c|c|}
\hline $\begin{array}{l}\text { Undergraduate Student } \\
\text { Graduate Student }\end{array}$ & $\begin{array}{l}\text { Group } 1 \\
(\mathrm{n}=30) \\
(\mathrm{n}=33)\end{array}$ & $\begin{array}{c}\text { Group } 2 \\
(n=16) \\
(n=15)\end{array}$ & $\begin{array}{l}\text { Group } 3 \\
(n=20) \\
(n=20)\end{array}$ & $\begin{array}{c}\text { Total } \\
(\mathrm{n}=66) \\
(\mathrm{n}=68)\end{array}$ & $F$ & $p$ & $\eta^{2}$ \\
\hline \multirow{2}{*}{ Age } & $28.07(10.69)$ & $29.56(11.69)$ & $23.10(4.48)$ & $27.21(9.28)$ & 9.08 & $.00 * *$ & .13 \\
\hline & $32.73(9.12)$ & $31.93(10.56)$ & $31.25(8.01)$ & $32.12(9.04)$ & 3.49 & .07 & .05 \\
\hline \multirow[t]{2}{*}{ Test Scores } & $86.73(8.36)$ & $83.00(8.07)$ & $82.90(8.55)$ & $84.67(8.44)$ & 1.39 & .26 & .04 \\
\hline & $88.97(5.60)$ & $87.33(8.05)$ & $85.95(6.46)$ & $87.72(6.49)$ & 1.23 & .30 & .04 \\
\hline \multirow[t]{2}{*}{ Positive Metacognitive Beliefs about Procrastination } & $2.78(.83)$ & $3.43(.90)$ & $4.02(.98)$ & $3.31(1.03)$ & 9.18 & $.00 * *$ & .23 \\
\hline & $2.33(.815)$ & $3.63(1.33)$ & $3.78(.87)$ & $3.04(1.18)$ & 18.87 & $.00 * *$ & .37 \\
\hline \multirow[t]{2}{*}{ Negative Metacognitive Beliefs about Procrastination } & $4.72(1.03)$ & $5.02(.69)$ & $3.95(1.24)$ & $4.56(1.10)$ & 5.64 & $.00 * *$ & .15 \\
\hline & $4.62(1.16)$ & $4.40(1.38)$ & $4.53(1.20)$ & $4.54(1.18)$ & .15 & .86 & .00 \\
\hline \multirow[t]{2}{*}{ Ed. Psychology Self- Efficacy } & $3.74(.69)$ & $3.52(.72)$ & $3.58(.91)$ & $3.64(.76)$ & .49 & .62 & .02 \\
\hline & $3.87(.53)$ & $3.61(.39)$ & $3.66(.61)$ & $3.75(.53)$ & 1.59 & .21 & .05 \\
\hline \multirow[t]{2}{*}{ Mastery-Approach } & $5.39(1.11)$ & $5.63(1.11)$ & $4.63(1.48)$ & $5.22(1.28)$ & 2.54 & .09 & .08 \\
\hline & $5.65(1.02)$ & $4.71(1.04)$ & $5.33(1.19)$ & $5.35(1.12)$ & 4.06 & $.02 *$ & .11 \\
\hline \multirow[t]{2}{*}{ Mastery-Avoidance } & $4.67(1.51)$ & $5.27(1.33)$ & $4.13(1.91)$ & $4.65(1.64)$ & 3.50 & $.04 *$ & .10 \\
\hline & $4.30(1.64)$ & $4.62(1.63)$ & $4.95(1.51)$ & $4.56(1.60)$ & .96 & .39 & .03 \\
\hline \multirow[t]{2}{*}{ Performance-Approach } & $3.39(1.58)$ & $3.48(1.73)$ & $3.93(1.60)$ & $3.58(1.61)$ & .38 & .69 & .01 \\
\hline & $2.73(1.75)$ & $2.93(1.87)$ & $3.70(1.77)$ & $3.06(1.81)$ & 1.72 & .19 & .05 \\
\hline \multirow[t]{2}{*}{ Performance-Avoidance } & $4.66(1.69)$ & $5.40(1.21)$ & $5.12(1.33)$ & $4.97(1.49)$ & 1.71 & .19 & .05 \\
\hline & $3.88(1.77)$ & $5.00(1.52)$ & $5.32(1.78)$ & $4.55(1.82)$ & 4.83 & $.01 *$ & .13 \\
\hline \multirow[t]{2}{*}{ Work-Avoidance } & $3.53(1.25)$ & $4.06(.72)$ & $4.60(1.47)$ & $3.98(1.28)$ & 4.19 & $.02 *$ & .12 \\
\hline & $2.63(1.13)$ & $3.47(1.09)$ & $3.94(1.18)$ & $3.20(1.26)$ & 8.68 & $.00 * *$ & .21 \\
\hline
\end{tabular}

Note: $*=p<.05, * *=p<.001 . d f=(2,62)$ for undergraduate students and $d f=(2,64)$ for graduate students. Group $1=$ Non-Procrastinators; Group $2=$ Passive Procrastinators; Group 3=Active Procrastinators. Age was used as covariate in the ANCOVA, but reported here for group comparison. 
1, $M=2.78$ ). However, active procrastinators (Group 3, $M=3.95$ ) reported a significantly lower level of negative metacognitive beliefs about procrastination than passive procrastinators (Group 2, $M=5.02, p=.007$ ) and the non-procrastinators (Group 1, $M=4.72, p=.028$ ). Furthermore, a significant difference was also found in the mastery-avoidance goal orientation between passive procrastinators (Group 2, $M=5.27$ ) and active procrastinators (Group 3, $M=4.13, p=.032$ ); and in the work-avoidance goal orientation between non-procrastinators (Group 1, $M=3.53$ ) and active procrastinators (Group 3, $M=4.60, p=.017$ ). No significant difference in test performance was found among the three procrastinator groups in the undergraduate students.

For the graduate students, the ANOVA results revealed a significant omnibus effect among the three procrastination groups on metacognitive beliefs, self-efficacy, achievement goals, and test performance (Wilk's $\lambda=.46, F_{(2,62)}=3.00, p=.001, \eta^{2}=.33$ ). As Table 3 shows, a significant difference was found among the three procrastination groups in positive metacognitive beliefs about procrastination $\left(F_{(2,64)}=18.87, p=.001 ; \eta^{2}=.37\right)$; mastery-approach goal orientation $\left(F_{(2,64)}=4.06, \quad p=.022 ; \quad \eta^{2}=.11\right)$; performance-avoidance goal orientation $\left(F_{(2,64)}=4.83, p=.011 ; \eta^{2}=.13\right)$; and work-avoidance goal orientation $\left(F_{(2,64)}=8.68, p=.001\right.$; $\left.\eta^{2}=.21\right)$.

Again, the Bonferroni analyses show that both active procrastinators (Group 3, $M=3.78, p$ $=.001$ ) and passive procrastinators (Group 2, $M=3.63, p=.001$ ) reported a significantly higher level of positive metacognitive beliefs about procrastination than the non-procrastinators (Group $1, M=2.33$ ). In addition, the non-procrastinators (Group 1, $M=5.65$ ) reported a significantly higher level of the mastery-approach goal orientation than passive procrastinators (Group 2, $M=4.71, p=.018$ ). However, the non-procrastinators reported a significantly lower level of the performance-avoidance goal orientation (Group 1, $M=3.88, p=.016$ ) and work-avoidance goal orientation (Group 1, $M=2.63, p=.001$ ) than active procrastinators (Group 3, $M=5.32, M=3.94$, respectively). No significant difference in test performance was found among the three procrastinator groups in the graduate students.

\section{Discussion and Conclusion.}

The present study used a self-regulated learning perspective to compare undergraduate and graduate students' procrastination types and associated motivation. The purpose was to better understand similarities and differences of procrastination behaviors and associated motivation in undergraduate and graduate students. The results contribute to research on procrastination and self-regulated learning and inform interventions addressing procrastination.

Results to the first research question on the relationships between procrastination types and motivation revealed three points of similarity of undergraduate and graduate students. The first similarity concerns the tendency and reason of procrastination. The results show that academic procrastination was more likely to occur in those who had stronger beliefs that procrastination was beneficial and would improve cognitive performance in both undergraduate and graduate students. The second similarity relates to the strength of the correlation between academic procrastination and students' positive beliefs about procrastination. For both undergraduate and graduate students, the correlation between positive metacognitive beliefs about procrastination and academic procrastination was the strongest among all the relations. Together, these findings suggest that students' positive metacognitive beliefs about the adaptive values of procrastination play a more important role in propagating academic procrastination than other motivation variables, such as self-efficacy and achievement goal orientations. 
The third similarity points to the purpose of procrastination. The results show that procrastinators in undergraduate and graduate students had a higher tendency to avoid performing worse than their peers and to minimize their efforts for academic tasks (Blunt \& Pychyl, 1998; Clark \& Hill, 1994; Ferrari, 1991; Ferrari \& Tice, 2000; Wolters, 2003). These findings demonstrate efficacy of the self-regulated learning perspective in the study of procrastination, and show that procrastination is a motivational problem that involves more than poor time management skills or trait laziness (Özer, 2011; Senécal et al., 1995). More importantly, these findings suggest that motivational and cognitive factors must be considered together to understand academic procrastination (Howell \& Buro, 2009; Muszynski \& Akamatsu, 1991; Steel, 2007). In particular, metacognitive beliefs about procrastination, performanceavoidance goal, and work-avoidance goal need to be addressed to help both undergraduate and graduate students battle against academic procrastination.

Also, interesting differences were found on the negative correlates with academic procrastination between undergraduate and graduate students. First, the results show that age was negatively related to academic procrastination for undergraduate students, but not for graduate students. This finding suggests that younger undergraduate students were more likely to procrastinate than their older counterparts who were mostly nontraditional students. This finding is consistent with the previous research that procrastination tendency reaches a peak for persons in their middle-to-late $20 \mathrm{~s}$ and declines until approximately age 60 (Ferrari, Johnson, \& McGown, 1995). This finding also implies the possibility that students may grow out of the procrastination problem as they become more experienced in school and more mature in life. Consequently, procrastination can be approached as a developmental problem in undergraduate students, as well as a flaw in personality trait (Özer, Demir, \& Ferrari, 2009; Jiao et al., 2011; Schouwenbury, 2004; Steel, 2007).

Second, a negative correlation was found between academic procrastination and masteryapproach goal orientation in the graduate students, but not in undergraduate students. It was a little surprising that no significant relation was found between academic procrastination and mastery-approach goal orientation in undergraduate students. However, the negative correlation found between academic procrastination and mastery-approach goal orientation in graduate students was expected. This finding suggests that procrastination was less likely to occur for the graduate students who seek to improve their knowledge and learn all there is to learn. The inverse relationship between academic procrastination and the mastery-approach goal is consistent with the previous research that a negative correlation exists between academic procrastination and a general mastery orientation (Schraw et al., 2007). As the previous results show, students who procrastinated were less likely to adopt the learning goal and make the effort to learn everything there is to learn (Howell \& Buro, 2009; Wolters, 2003), but more likely to adopt avoidance goal orientations (Howell \& Watson, 2007).

The present data presented mixed results regarding the relationships between test performance and procrastination. On the one hand, the present result supported the previous finding that undergraduate students who reported high on procrastination score achieved lower on test performance (Brinthaupt \& Shin, 2001; Jiao et al., 2011; Tice \& Baumeister, 1997; Wang \& Englander, 2010). These results demonstrated that procrastination has a negative effect on test performance. On the other hand, the present data show that there is no significant difference among the three different procrastination groups in both undergraduate and graduate participants, despite their differences in the motional variables, e.g., metacognitive beliefs about procrastination and achievement goals discussed above. These results were consistent with the 
previous findings that procrastination scores were positively related to academic behavior delays but unrelated to exam scores (Ferrari, 1992; Solomon \& Rothblum, 1984). These mixed results suggest that a complex relationship between procrastination and academic performance.

One possible explanation of the lack of influence of procrastination on test performance was the small sample size in each procrastination group in the present study, even though each group satisfied the minimum requirement (Table 3) for the parametrical data analysis procedure such as ANOVA and regression. Another possible reason might be that the deleterious consequences of procrastination on performance are cumulative (Ferrari et al., 1995) which might be better captured by measures of academic performance over time such as grade point average (GPA). The discrepancy noted between the present results and previous research does indicate that further research is necessary to understand at what point procrastination begins to affect performance (Pychyl, Morin, \& Salmon, 2000).

Similarly, differences were found in the correlations between active procrastination and motivation factors in undergraduate students and graduate students. For the undergraduate students, active procrastinators tended to be those who believed more in the usefulness of procrastination, had less concerns about uncontrollability of procrastination, and possessed lower mastery-approach goals. In contrast, for the graduate students, active procrastination tended to be those who were more confident about their ability to learn the class content. The correlates of active procrastination mostly concurred with the motivational factors identified in the existing research such as metacognitive beliefs and achievement goal orientations for undergraduate students (Howell \& Buro, 2009; Özer, 2011; Schraw et al., 2007; Steel, 2007; Wolters, 2003). However, the association of active procrastination with self-efficacy suggests student beliefs of their ability to learn the class content was a unique motive for graduate students to engage in active procrastination.

The positive correlation between student self-efficacy and active procrastination found in the present study is consistent with Chu and Choi's (2005) observation. This result was also confirmed by the regression analysis showing self-efficacy as the sole predictor of active procrastination. These results suggest that graduate students tended to procrastinate when they felt more confident with their abilities to accomplish academic tasks. According to Chu and Choi (2005), this is because active procrastinators were confident in their abilities to meet deadlines and complete the tasks under time pressure, so they intentionally postponed academic tasks and directed their attention toward more urgent issues at hand. However, these results are inconsistent with prior observations that students who were confident about their abilities to do well tended to start their academic work in a more timely manner (Bandura, 1986; Steel, 2007; Wolters, 2003). These conflicting results suggest that observations in the existing research are far from conclusive in regards to the relationships between self-efficacy and procrastination. Nevertheless, the present results show that different motivational factors need to be considered to understand active procrastination in undergraduate and graduate students.

In addition to the procrastination types, the present study examined associated motivational variables. Again, mixed results were found on students' positive metacognitive beliefs about procrastination. First, similarities were found in the undergraduate and graduate students who believed more about the usefulness of procrastination. These students reported a higher tendency to engage in academic procrastination. They tended to be younger in age within their group. They also tended to adopt lower mastery-approach goals but higher performanceavoidance goals and work-avoidance goals. At the same time, differences were found between undergraduate and graduate students regarding beliefs about the usefulness of procrastination. 
For the undergraduate students, those who held a stronger belief that procrastination was beneficial tended to have a higher active procrastination and lower performance on tests. For the graduate students, those who reported a stronger belief about the usefulness of procrastination tended to have a higher level of master-avoidance goal orientations. These students tended to try everything they can to avoid failure to learn all the materials, which may explain the reasons why procrastination occur to these students (Brownlow \& Reasinger, 2000; Jiao et al., 2011; Onwuegbuzie, 2000). These results demonstrate that students' positive metacognitive beliefs about procrastination were associated with maladaptive motivational and cognitive factors. Reducing the positive metacognitive beliefs about procrastination would help both undergraduate and graduate students deal with procrastination.

Similarly, differences were found regarding negative metacognitive beliefs about procrastination between undergraduate and graduate students. Among undergraduate students, those who were more concerned about the uncontrollability of procrastination were less likely to engage in active procrastination. In contrast, among the graduate students, those who were more concerned about the uncontrollability of procrastination tended to adopt a stronger masterapproach goal orientation. These findings suggest that reinforcing the negative metacognitive beliefs may help undergraduate students to reduce active procrastination and graduate students to adopt the mastery-approach goal which is most desirable to promote learning (Elliot \& McGregor, 2001; Fernie \& Spada, 2008; Howell \& Watson, 2007; Wolters, 2003).

Results to the second research question largely confirmed the findings of the first research question. Positive metacognitive beliefs about procrastination were the sole predictor of academic procrastination for both undergraduate and graduate students, even when self-efficacy and achievement goal orientations were considered. These findings suggest that metacognitive beliefs play a more important role in academic procrastination than self-efficacy and academic achievement goal orientations in undergraduate and graduate students. Therefore, an attempt to help students overcome academic procrastination may be more effective by focusing on students' beliefs of the usefulness of their procrastination.

Similar to the correlation results above, the regression results on active procrastination varied between undergraduate and graduate students. The results show that undergraduate students tended to engage in active procrastination when they were less concerned about the uncontrollability of procrastination and less oriented toward learning in class. These findings are inconsistent with Chu and Choi's (2005) characterization of active procrastination. Chu and Choi (2005; Choi \& Moran, 2009) posited that active procrastinators intentionally delayed academic tasks because they preferred time pressure, and they possess the confidence and ability to meet deadlines. However, the function of master-approach goal orientation as a negative predictor of active procrastination clearly shows that active procrastination is associated with maladaptive motivation value, and that the purpose of students engaging in active procrastination is not to learn and develop their competences. Apparently, more research is needed to examine the notion of active procrastination and address the question: Is active procrastination associated with desirable cognitive and motivational characteristics in undergraduate students?

The regression results on active procrastination show that educational psychology selfefficacy is a significant positive predictor to active procrastination in graduate students. This finding is consistent with Chu and Choi's (2005) observation of the positive correlation between self-efficacy and active procrastination. It suggests that students may intentionally delay academic tasks when they have strong beliefs about their abilities to learn the class materials. This finding demonstrates that active procrastination is associated with self-efficacy, which is 
often viewed as a desirable motivation variable (Bandura, 1986) in graduate students. Evidently, more research is needed to sort out procrastination among the high self-efficacy graduate students. One way to achieve this purpose is to conduct multivariate studies of procrastination that include ability and motivation. As Bandura (1997) suggested, students' self-efficacy beliefs have a significant impact on their task initiation, self-regulatory efforts, and academic performance when adequate levels of ability and motivation exist. This position suggests that the relationship of self-efficacy with task initiation, efforts, and academic performance is not straightforward, but mediated by a certain level of ability and motivation.

Again, results to the third research question revealed similarities and differences among the three procrastinator groups in undergraduate and graduate students. The group comparisons show that the passive procrastinators and active procrastinators in undergraduate and graduate students reported a significantly higher level of beliefs about the usefulness of procrastination and work-avoidance goal orientation than non-procrastinators. These results suggest that active procrastinators and passive procrastinators are similar in believing procrastination is useful. However, their intent to engage in procrastination is to get away with putting as little efforts as possible in achievement tasks (Elliot, 1999; Maehr, 1983; Nicholls, Patashnick, \& Nolen, 1985). These findings are consistent with previous research (Schraw et al., 2007; Wolters, 2003) that procrastination is an irrational delay, or avoidance, of academic tasks and a failure of selfregulation of the learning process (Senécal et al., 1995; Steel, 2007).

The group comparisons also reveal differences among the three procrastinator groups between undergraduate and graduate students. Among the undergraduate students, the active procrastinators were the youngest in age of the three procrastination groups, and they were significantly younger than the passive procrastinators. These findings suggest that among the undergraduate procrastinators, the younger students tended to engage in active procrastination while the older students tended to engage in passive procrastination. Also, active procrastinators reported the least concerns about the uncontrollability of procrastination among the three procrastinator groups; and their concerns were significantly lower than those of the nonprocrastinators and passive procrastinators. Furthermore, active procrastinators reported a significantly lower level of mastery-avoidance goal orientation than passive procrastinators. These findings are consistent with the results to the first and second research question discussed above. They suggest that the reasons undergraduate active procrastinators procrastinate relate to their minimal concern with the negative consequences of procrastination and failure to learn all of the class materials. In addition, these results support Chu and Choi's (2005) differentiation between active and passive procrastinators. In this case, active procrastinators are different from passive procrastinators in negative metacognitive beliefs about procrastination and masteryavoidance goal orientation. While a lower level of negative metacognitive beliefs about procrastination is consistent with active procrastinators' intentional delay of academic tasks (Chu $\&$ Choi, 2005), the influence of master-avoidance goal orientations in active procrastination has not yet been adequately examined (Elliot \& McGregor, 2001; Howell \& Buro, 2009; Howell \& Watson, 2007). Further research in this area will facilitate greater understanding of the nature of procrastination, achievement goal orientation, and self-regulated learning (Pintrich, 2000; Wolters, 2003).

Two differences stood out among the three procrastination groups in graduate students. Non-procrastinators reported a significantly higher level of mastery-approach goal orientations than passive procrastinators, but a significantly lower level of performance-avoidance goal orientations than active procrastinators. While the finding concerning the mastery-approach goal 
confirmed the negative correlation of the mastery-approach orientation with self-handicapping (Midgley \& Urdan, 1995; Midgley, Arunkamar, \& Urdan, 1996; Pintrich, 2000) and procrastination (Howell \& Watson, 2007; Wolters, 2003), the finding about the performanceavoidance goal orientation is inconsistent with the research that active procrastination was associated with adaptive values of procrastination (Chu \& Choi, 2005). Similar to the results for the undergraduate students, these results also challenged Chu and Choi's (2005) description that active procrastinators are more similar to non-procrastinators than to passive procrastinators, even though active procrastinators procrastinate to the same degree as passive procrastinators. More research is called to look into the inconsistent results between the present study and Chu and Choi's (2005) work in order to better understand the nature of active procrastination. For instance, the future research could use quantitative and qualitative designs to examine adaptive and maladaptive characteristics of active and passive procrastinators in the behavioral, motivational, and affective domains. One way to investigate the nature of active procrastination is to identify the procrastinators who are successful in managing their learning process and achieving superior academic performances; and then examine differences in the beliefs, affects, and behaviors of these successful procrastinators as compared to unsuccessful procrastinators and non-procrastinators.

Future research could also examine to what extent students' ability and motivation would be adequate so that self-efficacy enables them to exercise some control over their thoughts, feelings, and actions. At the same time, this research could also indentify to what extent, and under what conditions, students' ability and motivation would become inadequate so that their self-efficacy leads to underestimation of difficulty of a task while simultaneously overestimating the positive benefits of procrastination (Schraw et al., 2007). This line of research would advance research of procrastination and self-regulated learning. Practically, results of this research would help design interventions to help graduate students avoid overconfidence of their ability and consequently failing to self-regulate their learning (Pintrich, 2000; Senécal et al., 1995; Steel, 2007; Wolters, 2003).

In summary, the findings of the present study extend the research on procrastination by providing a more in-depth look at procrastination types and the associated motivation among undergraduate and graduate students simultaneously in one subject area. The present results suggest that students' beliefs about the usefulness of procrastination play a more important role in propagating academic procrastination than other motivation variables for both undergraduate and graduate students. In contrast, different motivational factors, including metacognitive beliefs, self-efficacy, and achievement goal orientations, were involved in active procrastination for undergraduate and graduate students. In addition, student age was related to procrastination types particularly in undergraduate students. Among the undergraduate procrastinators, the younger students were more likely to be active procrastinators, while the older students tended to be passive procrastinators. These results confirmed the traditional view that procrastination is related to undesirable factors that hinder learning (Day et al., 2000; Ferrari, 2001; Jiao et al., Knaus, 2000; Lay, 1990; Steel, 2007); but also offered mixed support to the notion that active procrastination is associated with adaptive values of procrastination (Chu \& Choi, 2005, Choi \& Moran, 2009) and motivational factors conductive to learning (Wolters, 2003, 2004). Clearly, more evidence is needed to demonstrate that procrastination is not a result of students' systematic underestimation of the difficulty of the task while simultaneously overestimating the positive benefits of procrastination (Schraw et al., 2007). 
The present results demonstrated that the self-regulated leaning perspective was useful in studying a complex phenomenon like procrastination. However, the present results should be interpreted with caution. The present study was limited to a relatively small sample observed in one subject area for a short period of time, and the cross-sectional design precluded causal inferences. Studies with larger samples across different subject areas, and tasks over time will expand the research on procrastination, motivation, and self-regulated learning. In particular, further research is needed to investigate the notion of active procrastination for a better understanding of the nature of procrastination. Also, more studies are needed to examine whether self-efficacy functions as a motivational factor that encourages students to procrastinate, or as a deterrent that discourages them to procrastinate in academic situations. The present study used a self-reported measure of procrastination. Future research might employ observation of actual procrastination behavior as an additional, confirmatory measure of student procrastination. The incorporation of such data would strengthen the results of future investigations of procrastination, motivation, and self-regulatory behaviors.

Despite the above limitations, the present results illustrate the importance of examining the relationships between procrastination, motivation, and self-regulated learning in the research of procrastination. They also suggest implications for educational practice. In particular, interventions designed to curtail academic procrastination among undergraduate students might be more effective if they focus on decreasing students' positive metacognitive beliefs about procrastination, and if they pair the younger students with non-traditional students. The present results also raised questions about the role of procrastination in the college classroom. One such question concerns whether teachers and students should be more accepting of procrastination, or even attempt to promote the "safe" active procrastination (Choi \& Moran, 2009). Although the present results are preliminary in nature, they clearly suggest that different variables need to be considered in future research and interventions to reduce procrastination in undergraduate and graduate students.

\section{References}

Ames, C. (1984). Competitive, cooperative, and individualistic goal structures: A motivational analysis. In R. Ames \& C. Ames (Eds.), Research on motivation in education (vol. 1, pp. 177207). New York: Academic Press.

Ames, C., \& Archer, J. (1988). Achievement goals in the classroom: Student learning strategies and achievement motivation. Journal of Educational Psychology, 18, 409-414.

Bandura, A. (1986). Social foundations of thoughts and action: A social cognitive theory. Englewood Cliffs, NJ: Prentice-Hall.

Bandura, A. (1997). Self-efficacy: The exercise of control. New York: Cambridge University Press.

Bernstein, P. (1998). Against the gods: The remarkable story of risk. New York: Wiley. 
Blunt, A., \& Pychyl, T. A. (1998). Volitional action and inaction in the lives of undergraduate students: State orientation, procrastination and proneness to boredom. Personality Individual Difference, 24, 837-846.

Brinthaupt, T. M., \& Shin, C. M., (2001), The relationship of academic cramming to flow experience. College Student Journal, 35(3), 457-272.

Brownlow, S., \& Reasinger, R. (2000). Putting off until tomorrow what is better done today: Academic procrastination as a function of motivation toward college work. Journal of Social Behavior \& Personality, 15(5), 15-34.

Burns, L., Dittmann, K., Nguyen, N., \& Mitchelson, J. (2000). Academic procrastination, perfectionism, and control: Associations with vigilant and avoidant coping. Journal of Social Behavior \& Personality, 15(5), 35-46.

Choi, J. N., \& Moran, S. V. (2009). Why not procrastinate? Development and validation of a new active procrastination scale. The Journal of Social Psychology, 149(2), 195-211.

Chu., A. H. C., \& Choi, J. N. (2005). Rethinking procrastination: Positive effects of "active" procrastination behavior on attitude and performance. The Journal of Social Psychology, 145(3), 245-264.

Collins, K., Onwuegbuzie, A., \& Jiao, Q. G. (2008). Reading ability as a predictor of academic procrastination among African American graduate students. Reading Psychology, 29(6), 493507.

Collins, K. M. T., \& Veal, R. E. (2004). Off-campus adult learners' levels of library anxiety as a predictor of attitudes toward the Internet. Library \& Information Science Research, 26(1), 5-14.

Day, V., Mensink, D., \& O'Sullivan, M. (2000). Patterns of academic procrastination. Journal of College Reading and Learning, 30, 120-134.

Dweck, C. (1991). Self-theories and goals: Their role in motivation, personality, and development. In R. A. Dienstbier (Ed.), Nebraska Symposium on Motivation (Vol. 38, pp. 195273). Lincoln: University of Nebraska Press.

Elliot, A. J. (1999). Approach and avoidance motivation and achievement goals. Educational Psychologist, 34, 169-189.

Elliot, A. J., \& Church, M. A. (1997). A hierarchical model of approach and avoidance achievement motivation. Journal of Personality and Social Psychology, 72, 218-232.

Elliot, A. J., \& Harachiewicz, J. M. (1996). Approach and avoidance achievement goals and intrinsic motivation: A meditational analysis. Journal of Personality and Social Psychology, 70, 461-475. 
Cao, L.

Elliot, A. J., \& McGregor, H. A. (2001). A 2 x 2 achievement goal framework. Journal of Educational Psychology, 80(3), 501-519.

Ellis, A., \& Knaus, W. J. (1977). Overcoming procrastination. New York: Signet.

Fernie, B. A., \& Spada, M. M. (2008). Metacognitions about procrastination: A preliminary investigation. Behavioural and Cognitive Psychotherapy, 36, 359-364.

Fernie, B. A., Spada, M. M., Nikcevic, A. V., Georgiou, G. A., \& Moneta, G. B. (2009). Metacognitive beliefs about procrastination: Development and concurrent validity of a selfreport questionnaire. Journal of Cognitive Psychotherapy, 23(4), 283-293.

Ferrari, J. R. (1991). Self-handicapping by procrastinators: Protecting self-esteem, social esteem, or both? Journal of Research in Personality, 25, 245-261.

Ferrari, J. R. (1992). Procrastinators and perfect behavior: An exploratory factor analysis of self presentation, self-awareness, and self-handicapping components. Journal of Research in Personality, 26, 75-84.

Ferrari, J. R. (1994). Dysfunctional procrastination and its relationship with self-esteem, interpersonal dependency, and self-defeating behaviors. Personality and Individual Differences, $17,673-679$.

Ferrari, J. R. (2001). Procrastination as self-regulation failure of performance: Effects of cognitive load, self-awareness, and time limits on "working best under pressure." European Journal of Personality, 15, 391-406.

Ferrari, J. R., Johnson, J. L., \& McGown, W. G. (1995). Procrastination and task avoidance: Theory, research, and treatment. New York: Plenum Press.

Ferrari, J. R., O’Callaghan, J., \& Newbegin, I. (2005). Prevalence of procrastination in the United States, United Kingdom, and Australia: Arousal and avoidance delays among adults. North American Journal of Psychology, 7, 2-6.

Ferrari, J. R., \& Tice, D. M. (2000). Procrastination as a self-handicap for men and women: A task-avoidance strategy in a laboratory setting. Journal of Research in Psychology, 34, 73-83.

Ferrari, J. R., Parker, J. T., \& Ware, C. B. (1992). Academic procrastination: Personality correlates with Myers-Briggs types, self-efficacy, and academic locus of control. Journal of Social Behavior and Personality, 7, 595-602.

Field, A. (2009). Discovering statistics using SPSS (3 ${ }^{\text {rd }}$ ed.). Los Angeles: Sage.

Fritzsche, B. Rapp, B. Y., \& Hickson, K. C. (2003). Individual differences in academic procrastination tendency and writing success. Personality and Individual Differences, 35 15491558. 
Cao, L.

Harriott, J., \& Ferrari, J. (1996). Prevalence of procrastination among samples of adults. Psychological Reports, 78, 611-616.

Howell, A. J., \& Buro, K. (2009). Implicit beliefs, achievement goals, and procrastination: A meditational analysis. Learning and Individual Differences, 19, 151-154.

Howell, A. J., \& Watson, D. C. (2007). Procrastination: Associations with achievement goal orientation and learning strategies. Personal and Individual Differences, 43, 167-178.

Jiao, Q. G., DaRos-Voseles, D. A., Collins, K. M. T., \& Onwuegbuzie, A. J. (2011). Academic procrastination and the performance of graduate-level cooperative groups in research methods courses. Journal of the Scholarship of Teaching and Learning, 11(1), 119-138.

Klassen, R. M., Ang, R. P., Chong, W. H., Krawchuk, L. L., Huan, V. S., Wong, I. Y. F., \& Yeo, L. S. (2010). Academic procrastination in two settings: Motivation correlates, behavioral patterns, and negative impact of procrastination in Canada and Singapore. Applied Psychology: An International Review, 59(3), 361-379.

Knaus, W. J. (2000). Procrastination, blame, and change. Journal of Social Behavior and Personality, 15, 153-166.

Lay, C. H. (1990). Working to schedule on personal projects: An assessment of personal-project characteristics and trait procrastination. Journal of Social Behavior and Personality, 5, 91-103.

Lay, C. H., Edwards, J. M., Parker, J. D., \& Endler, N. S. (1989). An assessment of appraisal, anxiety, coping, and procrastination during an examination period. European Journal of Personality, 3, 195-208.

Lee, E. (2005). The Relationship of motivation and flow experience to academic procrastination in University Students. Journal of Genetic Psychology, 166(1), 5-14.

Maehr, M. L. (1983). On doing well in science: Why Johnny no longer excels, why Sarah never did. In S. Paris, G. Olson, \& H. Stevenson, (Eds.), Learning and motivation in the classroom (pp. 179-120). Hillsdale, NJ: Erlbaum.

McGregor, H. A., \& Elliot, A. J. (2002). Achievement goals as predictors of achievementrelevant processes prior to task engagement. Journal of Educational Psychology, 94, 381-395.

Meece, J., \& Holt, K. (1993). A pattern analysis of students' achievement goals. Journal of Educational Psychology, 85, 582-590.

Middleton, M., \& Midgley, C. (1997). Avoiding the demonstration of lack of ability: An underexplored aspect of goal theory. Journal of Educational Psychology, 89, 710-718. 
Cao, L.

Midgley, C., Arunkumar, R., \& Urdan, T. (1996). If I don't do well tomorrow, there's a reason: Predictors of adolescents' use of academic self-handicapping behavior. Journal of Educational Psychology, 88, 423-434.

Midgley, C., Kaplan, A., \& Middleton, M. (2001). Performance-approach goals: Good for what, for whom, under what circumstances, and at what cost? Journal of Educational Psychology, 93, 77-86.

Midgley, C., \& Urdan, T. (1995). Predictors of middle school students' use of self-handicapping strategies. Journal of Early Adolescence, 15, 389-411.

Milgram, N., Dangour, W., \& Raviv, A. (1992). Situational and personal determinants of academic procrastination. Journal of General Psychology, 11, 123-133.

Moller, A. C., \& \& Elliot, A. J. (2006). The 2 x 2 achievement goal framework: An overview of empirical research. In A. V. Mittel (Ed.), Focus on educational psychology (pp. 307-326). Hauppauge, NY: Nova Science.

Morgan, G.A., Leech, N.L., Gloechner, G.W., \& Barrett, K.C. (2011). SPSS for introductory and intermediate statistics $\left(4^{\text {th }}\right.$ ed.). New York: Routledge.

Muszynski, S., and Akamatsu, T. (1991). Delay in completion of doctoral dissertations in clinical psychology. Professional Psychology: Research and Practice, 22, 119-123.

Nicholls, J.G., Patashnick, M., \& Nolen, S.B, (1985). Adolescents' theories of education. Journal of Educational Psychology, 77, 683-692.

Nietfeld, J. L., Cao, L., \& Osborne, J. W. (2006). The effect of distributed monitoring exercises and feedback on performance and monitoring accuracy. Metacognition and Learning, 2, 159179.

Ommundsen, Y. (2001). Self-handicapping strategies in physical education classes: The influence of implicit theories of the nature of ability and achievement goal orientations. Psychology of Sport and Exercise, 2, 139-156.

Onwuegbuzie, A. (2000). Academic procrastinators and perfectionistic tendencies among graduate students. Journal of Social Behavior and Personality, 15, 103-109.

Onwuegbuzie, A. (2004). Academic procrastination and statistics anxiety. Assessment \& Evaluation in Higher Education, 29(1), 3-19.

Onwuegbuzie, A. J., \& Collins, K. M. T. (2001). Writing apprehension and academic procrastination among graduate students. Perceptual and Motor Skills, 92, 560-562.

Onwuegbuzie, A., \& Jiao, Q. G. (2000). I'll go to the library tomorrow: The role of procrastination in library anxiety. College and Research Library, 61(1), 45-54. 
Cao, L.

Özer, B. U. (2011). A Cross Sectional Study on Procrastination: Who Procrastinate More? 2011 International Conference on Education, Research and Innovation, IPEDR, 18, 34-37.

Özer, B., Demir, A., \& Ferrari, J. (2009). Exploring Academic Procrastination Among Turkish Students: Possible Gender Differences in Prevalence and Reasons. Journal of Social Psychology, 149(2), 241-257.

Pintrich, P. R. (2000). The role of goal orientation in self-regulated learning. In M. Boekaerts, P. R. Pintrich, \& M. Zeidner (Eds.), Handbook of self-regulation. San Diego: Academic Press.

Prohaska, V., Morrill, P., Atiles, I., \& Perez, A. (2000). Academic procrastination by nontraditional students. Journal of Social Behavior and Personality, 15, 125-134.

Pychyl, T. A., Morin, R. W., \& Salmon, B. R. (2000). Procrastination and the planning fallacy: An examination of the study habits of university students. Journal of Social Behavior and Personality, 15(5), 135-150.

Rhodewalt, F. (1994). Conceptions of ability, achievement goals, and individual differences in self-handicapping behavior: On the application of implicit theories. Journal of Personality, 62, $67-85$.

Rothblum, E. D., Solomon, L. J., and Murakami, J. (1986). Affective, cognitive, and behavioral differences between high and low procrastinators. Journal of Counseling Psychology, 33, 387394.

Schouwenburg, H. C. (2004). Academic procrastination: Theoretical notions, measurement, and research. In H. C. Schouwenburg, C. H. Lay, T. A. Pychyl, \& J. R. Ferrari (Eds.), Counseling the procrastinator in academic settings (pp. 3-17). Washington, DC: American Psychological Association.

Schraw, G., Wadkins, T., \& Olafson, L. (2007). Doing the things we do: A grounded theory of academic procrastination. Journal of Educational Psychology, 99(1), 12-25.

Senécal, C., Julien, E., \& Guay, F. (2003). Role conflict and academic procrastination: A selfdetermination perspective. European Journal of Social Psychology, 33, 135-145.

Senécal, C., Koestner, R., \& Vallerand, R. J. (1995). Self-regulation and academic procrastination. Journal of Social Psychology, 135(5), 607-619.

Seo, E. (2008). Self-efficacy as a mediator in the relationship between self-oriented perfectionism and academic procrastination. Social Behavior \& Personality: An International Journal, 36(6), 753-764. 
Cao, L.

Shoham-Saloman, V., Avner, R., \& Neeman, R. (1989). You're changed if you do and changed if you don't: Mechanisms underlying paradoxical interventions. Journal of Consulting and Clinical Psychology, 57, 590-598.

Sommer, W. G. (1990). Procrastination and cramming: How adept students ace the system. Journal of American College Health, 39, 5-10.?????

Solomon, L. J., \& Rothblum, E. D. (1984). Procrastination Assessment Scale- Students (PASS). In J. Fischer \& K. Corcoran (Eds.), Measures for clinical practice (pp. 446-452). New York: The Free Press.

Spada, M. M., Hiou, K., \& Nikcevic, A. V. (2006). Metacognitions, emotions, and procrastination. Journal of Cognitive Psychotherapy, 20, 319-326.

Steel, P. (2007). The nature of procrastination: A meta-analytic and theoretical review of quintessential self-regulatory failure. Psychological Bulletin, 133, 65-94.

Tabachnick, B.G., \& Fidell, L.S. (2001). Using multivariate statistics, (4 ${ }^{\text {th }}$ ed.). Boston: Pearson.

Tan, C., Ang, R., Klassen, R., Lay See, Y., Wong, I., Huan, V., et al. (2008). Correlates of academic procrastination and students' grade goals. Current Psychology, 27(2), 135-144.

Tice, D., \& Baumeister, R. F. (1997). Longitudinal study of procrastination, performance, stress, and health: The cost and benefits of dawdling. Psychological Science, 8, 454-458.

Wang, Z., \& Englander, F. (2010). A cross-disciplinary perspective on explaining student performance in introductory statistics -- What is the relative impact of procrastination? College Student Journal, 44(2), 458-471.

Wells, A. (2000). Emotional disorders and metacognition: Innovative cognitive therapy. Chichester, UK: Wiley.

Wells, A., \& Matthews, G. (1994). Attention and emotion: A clinical perspective. Hover, UK: Erlbaum.

Wells, A., \& Matthews, G. (1996). Modelling cognition in emotional disorder: The S-REF model. Behaviour Research and Therapy, 34, 881-888.

Wolters, C. A. (2003). Understanding procrastination from a self-regulated learning perspective. Journal of Educational Psychology, 95(1), 179-187.

Wolters, C. A. (2004). Advancing achievement goal theory: Using goal structures and goal orientations to predict students' motivation, cognition, and achievement. Journal of Educational Psychology, 96(2), 236-25. 